\title{
Pop-Up Research Unit (\#PUPRU): Technology Strategy in Action
}

\author{
Dr Yun Chen, Dr Marie Griffiths, Mr Richard Dron \\ Centre for Digital Business, Salford Business School \\ The Crescent, University of Salford, M5 4WT, United Kingdom \\ Email: Y.Chen@salford.ac.uk; M.Griffiths@salford.ac.uk; R.M.Dron@salford.ac.uk
}

\begin{abstract}
Predicted key business IT trends through to 2020 acknowledge that there will be increased adoption of disruptive technologies that will impact within business contexts (Gartner (1), 2015). These include moves to smallscreen marketing, rising value of big data intelligence and increased use of social systems. However, IT penetration and the literacy gaps between advanced and emerging economies, as well as social and organisational issues associated with technological implementation of business strategy, provide challenges to the adoption of these trends. Strategy As Practice (SAP) presents a potential solution. It is concerned with the practice of strategising, including both the formulation of strategy and implementation that delivers strategic renewal and change. Through the "doing of strategy", organisations not only gain an insight into strategic management from theoretical level, but also can focus on micro-level social activities, process and practices that characterise both organisational strategy and strategising. In this paper, the Pop-Up Research Unit (\#PUPRU), a newly-established mobile research centre in the Salford Business School (SBS) will be discussed. It aims to adopt a SAP approach to inform business strategy. Three disruptive technologies - Beacon, Raspberry Pi and 3D printer - available as part of \#PUPRU will be examined. Future experiments that will be carried in various business scenarios and live projects evaluating how these digital disrupters can be employed will also be considered.
\end{abstract}

Keywords: \#PUPRU, Disruptive Technologies, Technology Strategy, Strategy as Practice (SAP), 3D Printing, Beacon, Raspberry $P i$

\section{INTRODUCTION}

In business "Disruptive Technologies" have become a buzz term describing a change and shift in the importance of IT in strategy. As businesses start to implement digital platforms based on disruptive technologies, and consumers spend greater time using digital platforms in their daily lives, it has become increasingly important to establish appropriate IT strategies to drive business efficiency and profitability. This paper will explore the impact of disruptive technologies in business, challenges of establishing IT strategies within organisations and Strategy As Practice (SAP) as a potential solution. This will provide a background context to the Pop-Up Research Unit (\#PUPRU).

\subsection{Emerging Technologies in Business Environment}

According to Christensen (Christensen, 1997), disruptive technology is a "new emerging technology that unexpectedly displaces an established one". For example, the personal computer displaced the typewriter changing the working and communication practices; smartphones have largely replaced cell phones because of portability and functionality which disrupts a wide range of industries, such as the manufacture of cameras, MP3 players, calculators and GPS devices.

In a business context, disruptive technologies are essentially new digital goods and services that revolutionise, change and disrupt the accepted method of performing business activities and transactions (Accenture, 2106). These innovations can transform business process and drive competitiveness with both positive and negative effects. Technological leadership is the key primary source of "First Mover" and 'Fast Followers" (Wunker, 2012). The positive impact of disruptive technologies in business is that they create a culture of continued innovation and fluidity in operational strategies. Businesses which are able to foresee technological trends and integrate appropriate technologies into their business strategy can evolve and align themselves with market and benefit a from self-driven disruption. All disruptive technologies have the potential to be the "next" big thing' and this creates significant opportunity, such as with past disrupters like the Internet and Google.

However, when digital disruption is unforeseen, the impact can drastically impact business revenues. For example, the GAME group closed 277 stores in the UK and Ireland in 2012 (BBC, 2012) when consumers habits shifted towards increased downloading of games. In the UK the EE 2015 third quarter results showed a $10.3 \%$ collapse in revenues from voice minutes as customers moved to VOIP communication through social media apps like Facebook Messenger, WhatsApp, and WeChat (Business Insider, 2015). Desktop PCs and 
laptop sales declined by $9.5 \%$ in 2015 with the increased global demand for tablets and smartphones; it is simply not a necessity for many to own a large-screen device anymore when there are cheaper mobile alternatives (Gartner (2), 2015). Fear that a new service could completely disrupt an existing business is a strong motivator to align IT with business strategy. This will be discussed in detail in the following section.

\subsection{Technology Strategy in Organisations}

IT has become a key business function for most organisations: many have great expectations of their investment in technologies to deliver future benefits to the business and achieve 6 strategic business objectives:

- Operational excellence

- New products, services, and business models

- Customer and supplier intimacy

- Improved decision making

- Competitive advantage

- Survival

In order to achieve these objectives, IT must be aligned to and effectively support business strategy. This degree of alignment is critical to both the success of the business, the effective use of its resources, and in turn, the perceived value of the IT implementation. However, there are 2 principal difficulties:

1. In practice, there are very few instances of business-oriented IT strategies. Most are either entirely technology-centric or focused purely on technology products and services;

2. The impact of technology on business is difficult to evaluate because it affects multiple aspects of the organisation, such as culture, people and legislation.

Concern about the gap between the theory of what people do and what actually happens within an organisation has given rise to the "practice" approach in management literature. As researches in the field of Strategy As Practice (SAP) suggest, business strategy is not necessarily about analysis and planning, but understanding how strategy operates both as a way of thinking and a way of acting so organisations can deliver value to their customers and increase their competitive success (Wyatt-Haines, 2007). SAP as a research topic is concerned with the "doing of strategy" (Pearlson et al., 2016):

- Who does it?

- What do they do?

- How they do it?

- What do they use?

- What implications does this have for shaping strategy?

While people do strategy, strategy theory is populated by multivariate analyses of firm or industry-level effects upon firm performance. There is an absence of human actors and their actions in most strategic theory, even in those that purport to examine the internal dynamics of the firm, such as the resource-based view (Johnson et al. , 2015). In order to undertake a deeper exploration on how disruptive technologies can positively influence business at a strategic level, Salford Business School (SBS) has established the Pop-Up Research Unit (\#PUPRU). The aim is to undertake both technology strategy research and engage with relevant industrial and public sectors partners through SAP theory.

\section{II. \# PUPRU}

\subsection{Introduction to \#PUPRU}

The Popup Research Unit (\#PUPRU) is a bespoke robust mobile display space intended for regular ad hoc installation in a range of public spaces including the high street, inside shopping malls, the foyers of large business premises, and at education institutions.

The digital revolution has significantly impacted traditional business. The unit provides a creative platform to support research into $4 \mathrm{G}$ retailing, digital marketing and the digital high street. Focus is on business exploitation, implementation and integration of a range of digital technologies, tools and methods, such as 3D scanning and printing, mobile beacon technologies and Raspberry Pi. Through these technologies, the Unit will look to capture data in relation to retailing practice, personal digital footprints, e-behaviour and e-supply chains. In the following section, experiments undertaken with \#PUPRU using key technologies are discussed and potential business scenarios explored. 


\subsection{PUPRU Technologies (1): 3D Printing Technology}

\subsubsection{Introduction to 3D Printing and its Use in Industries}

The rapid development and increased affordability of 3D printing, also known as additive manufacturing, has attracted much attention in recent years. Gibson et al (2010) state that the term "3D printing' refers to the layerby-layer creation of physical objects based on digital files that represent their design. It has made the technology into a viable tool for business and consumer use.

3D printing technology has evolved since it was first introduced at the end of the 80s by Charles Hull, when it was originally called Rapid Prototyping Technology (Luxexcel, 2016). During the first years, 3D printers were solely used to create prototypes; this is still common practice in the fields of construction and architecture, aerospace and automotive industries (Stratysis, 2013; Wohlers \& Gornet, 2011). 3D printers have become increasingly more reliable and powerful so that it is possible to develop final products as opposed to models or prototypes. This means that there has been a shift in $3 \mathrm{D}$ printing towards the production of goods, as opposed to a prototype development. This has benefited business as well as shifting consumer habits. People have started to use open source platforms such as Thingiverse (Thingiverse, 2106) to download designs to print. These are free and easy to use, with numerous models to print that have practical uses. Business can also benefit from 3D printing technology by either providing final products (addictive manufactory) or Internet retail. The ability to quickly reproduce detailed parts raises efficiency, lowers labour costs and has an impact on multiple businesses; these include the global manufacturing industry, jewellery and toy production, dental reconstructions, medical and health care. Some key benefits identified by AEB White Paper (AEB, 2014) of additive manufacturing include:

1. Waste reduction: Traditional manufacturing processes involve the removal of material through sanding or milling, whereas additive manufacturing only consumes the materials that are actually needed (Khajavi, et al, 2014; Holmström et al, 2010);

2. Product customisation and bespoke designs to order: 3D printing allows manufacture of individual bespoke products; hearing aid shells which fit recipient, implants and prosthetic devices, surgical instruments, tissue engineering, pharmaceuticals, dosage forms, medical and dental devices (Ventola (1), 2014; Ventola (2), 2014). Equally, it allows printing out replacement parts as needed (New Scientist, 2012) cutting requirements for storage space and to carry spares.

3. Reduction of $\mathrm{CO} 2$ emissions: 3D printing technology makes it possible to construct lighter components that reduce CO2 emissions. Karagol (2014) discusses how 3D printing technology is used in the aerospace industry to manufacture aircraft parts, that drives tooling, inspection, maintenance, assembly and inventory management (Karagol 2014, Wohlers \& Gornet, 2011).

3D printing can be used to transform online retailing. Retailers can sell blueprints, or downloadable design plans, those consumers can purchase on the web and print with their own 3D printers or at 3D print shops. The world's first 3D print shop opened in Zurich in 2012 (3D-MODEL, 2016) and additional shops have since opened in Munich and Vienna in 2014. In these shops the bespoke nature of the final print has increased so the design can be adapted to improve and modify functionality. Equally, electronic transmission of digital design plans for local production eliminates customs duties. An example of this is found in Nike who have marketed the first athletic shoe with 3D-printed components for download (Digital Trends, 2015), with templates for shoes that can be printed out overnight. Besides industry and business usage, 3D scanning and printing can be used for educational purposes in school and universities. Teachers and students can combine engineering, maths, design process and history.

It is clear that $3 \mathrm{D}$ printing has the potential to fundamentally revolutionise manufacturing in a wide range of business contexts. However, as with all other emerging technologies, implementation in certain contexts faces challenges that are not just technological, but ethical, organisational and political. For some organisations who by nature have had always had a traditional method of work, an emerging technology may create a way of working that may not be considered in their operating procedures. This may in effect force them to rethink requirements and establish new policies and procedures.

Issues with 3D printing technology include security, liability and intellectual property protection. To address and understand these issues, \#PUPRU will be taken into industry situations to understand how 3D printing disrupts the supply chain and logistics of the manufacturing industry.

\subsubsection{D Printers in \#PUPRU}


\#PUPRU has two Formlab Form 1+ 3D Printers (Figure 2.1 below). The supplier claims that it is a complete end-to-end system allowing users to 3D print from the convenience of their desktop (Formlabs, 2016). It uses PreForm, a software package designed to prepare any .STL or .OBJ for printing. Once a file has been prepared for 3D printing, a specific resin type can be selected. After a part has been printed, it will be coated with excess liquid resin. Users remove models from the build platform and then wash parts in isopropyl alcohol $(90 \%$ or above) for 20 minutes. Once dried, users can easily remove the part using cutters and the print is ready for use.

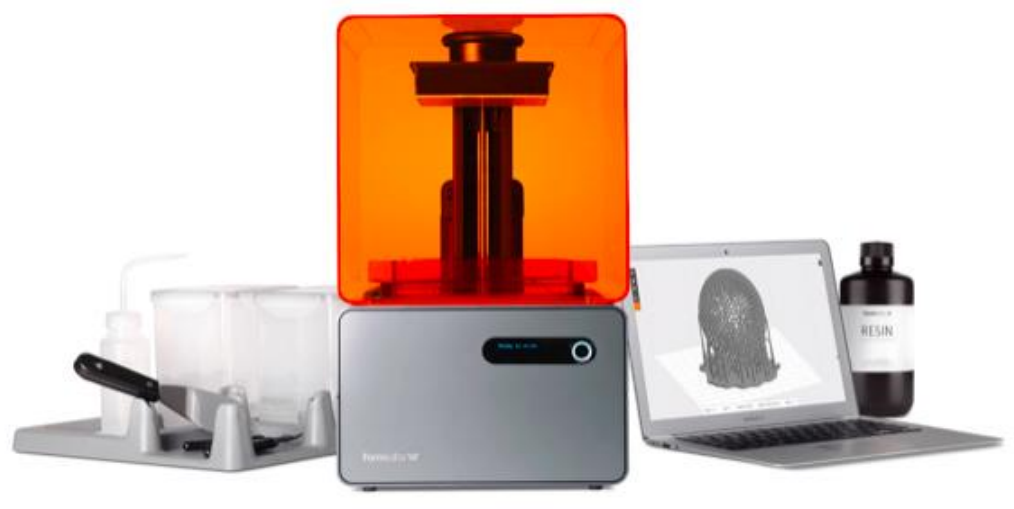

Figure 2.1 Formlab 3D Printer Set (Formlabs 2, 2016)

3D printing experiments have been undertaken by SBS staff to print some final products, such as butterfly clip, Apple USB case, and bookmark, as illustrated in Figure 2.2 below. The 3D digital technology was exhibited at the school Creative Entrepreneur event on 25 Nov 2015 at Media City UK (Creative Entrepreneur, 2015), an event celebrating the creative and digital economy.
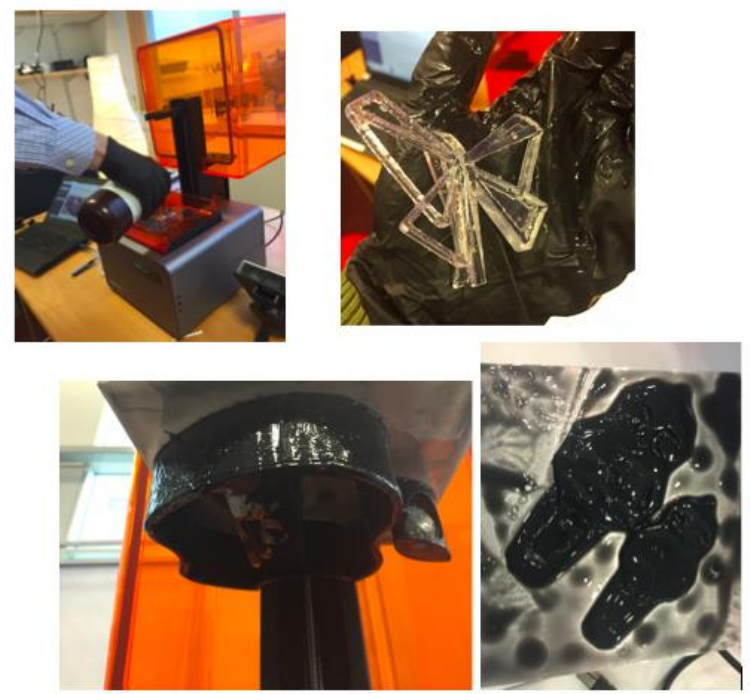

Figure 2.2 Products printed by Formlab 1+

Key lessons learned from this 'technology trial' include:

- Software is user friendly, easy to operate with clear instructions within the interface.

- $\quad$ Printing procedure is time-consuming, unsuitable for mass production. For example the butterfly model in Figure 2 has 1187 layers which is a relatively simple model. In medium resolution, it took 3 and half hours to print and 30 minutes to finish the post-printing (cutting supporting materials, cleaning the building platform etc.). When 'fast print' mode is used, the printing time reduces by around $40 \%$ to roughly 2 hours.

- The product is resin-efficient, but the product quality is rough and unfinished.

One doctoral research is currently being undertaken in SBS is investigating the impact of 3D printing implementation factors on supply chain designs with the overall aim of developing an addictive manufacture implementation framework. 


\subsection{PUPRU Technologies (2): Raspberry Pi}

\subsubsection{Introduction to 3D Printing and its Use in Industries}

Raspberry Pi is a low cost, credit-card sized computer that plugs into a monitor or TV, and uses a standard keyboard and mouse. It is a device that enables people of all ages to explore computing, and to learn how to program in languages like Scratch and Python. It can do the majority of things expected from a desktop computer, such as browsing the internet, playing high-definition video, to making spreadsheets, wordprocessing, and playing games (Raspberry Pi, 2016).

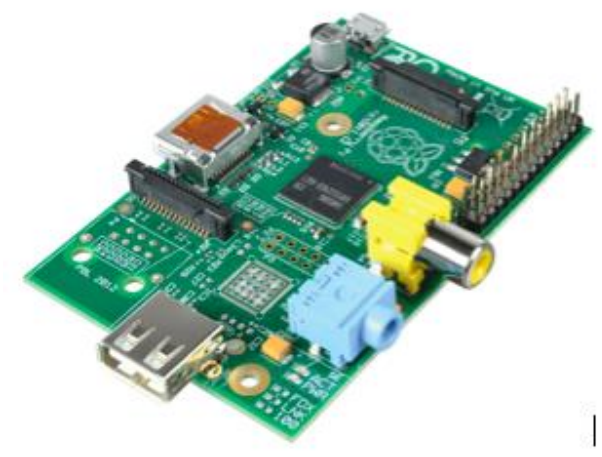

Figure 2.3 Raspberry Pi (Raspberry Pi, 2016)

Raspberry Pi has been designed to be used for educational purposes for creative teaching, learning and making. Although created to assist the teaching of basic computer science in schools, the device's low cost means it is increasingly used as a budget PC alternative in other industrial fields and to drive technology for internal business processes. Eben Upton, a chip architect at Broadcom and a founder of the Raspberry Pi Foundation, says the device is particularly useful in certain functions such as programming displays for digital signage. "It is actually very suitable for industrial uses, especially for industrial control processes," he argued. "The Pi is as powerful as or more powerful than what is currently being used" (Techradar, 2013).

There are many innovative things people could do with Raspberry Pi (ITPro, 2016), such as Makeshift face recognition, a Pi-powered lego (aokley.com, 2013) and Retro gaming / ZX spectrums. That said, there is little literature to show how Raspberry Pi can be embedded into business strategy.

\subsubsection{Raspberry Pi in \#PUPRU}

\#PUPRU has three Raspberry 1s, which have 40-pin GPIO headers, 4 USB 2.0 ports, 1SD card socket, audio input and a camera set socket. Key advantages identified through the experiments with Raspberry Pi include:

- Cost-efficiency and portability - Available from around $£ 25$, the Raspberry Pi is essentially a credit card-sized PC.

- Energy-efficient - The device can be powered by $5 \mathrm{v}$ micro USB.

- Functional with creative input/output channels - An author has successfully developed game controllers which can be connected to a Raspberry Pi to play the games (see Figure 2.4 below).

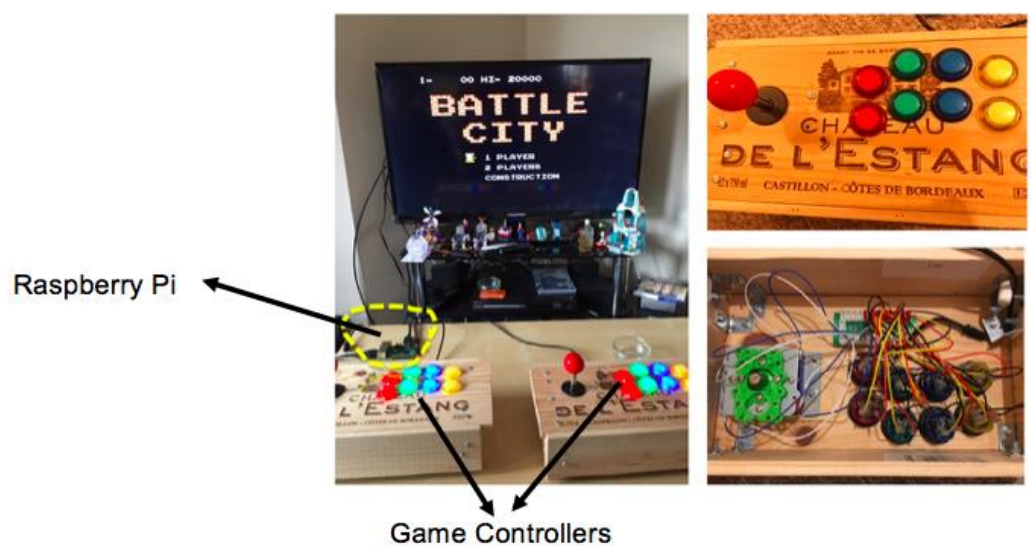

Figure 2.4 Raspberry Pi Game Set 


\subsection{3 \#PUPRU in Action: Raspberry Pi}

Based on the key advantages identified above, the authors suggest that Raspberry Pi has potential to be used in the public sectors to help achieve strategic aims and solve problems faced at a strategic level. An example is within the NHS whose strategic aim is outlined as follows:

"In order to preserve the values that underpin it, NHS must change to survive. Change. Change does not mean top-down reorganisation. Instead 'It means a reshaping of services to put patients at the centre and to better meet the health needs of the future'. There are opportunities to improve the quality of services for patients whilst also improving efficiency, lowering costs, and providing more care outside of hospitals. These include refocusing on prevention, putting people in charge of their own health and healthcare, and matching services more closely to individuals' risks and specific characteristics. To do so, the NHS must harness new, transformational technology and exploit the potential of transparent data as other industries have. We must be ready and able to share these data and analyses with the public and to work together with them to design and make the changes" (NHS, 2013).

The paper states there are three main future pressures on health service as illustrated in Figure 2.5 below:

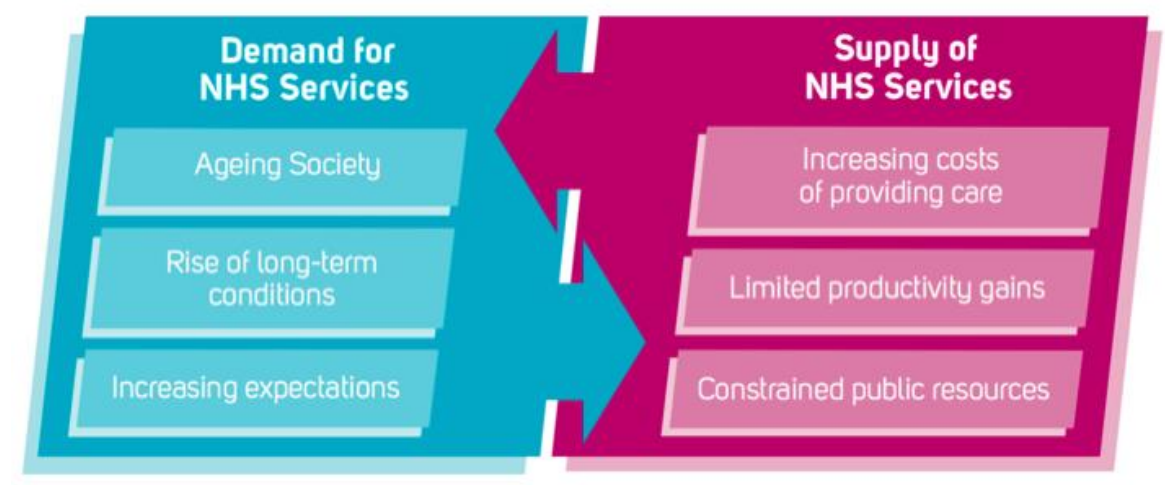

Figure 2.5 NHS Demand and Challenges (NHS, 2013)

Studies suggest that older patients account for the majority of health expenditure. One analysis found that health care expenditure for people over 75 was 13-times greater than to the rest of the adult population (Imison et al., 2012). Nearly two-thirds of people admitted to hospital are over 65 years old. The flexible input/output channels of the Raspberry Pi, such as the speaker, camera and button input may help elderly patient to participate and improve service quality, in a cost and energy effective manner.

To take this innovative idea to action, several meetings and correspondences have been conducted between SBS and the NHS Salford Clinical Commissioning Group. Conversations have focused on how disruptive technologies can help the NHS achieve their strategic objectives. The NHS Engagement Manager, Citizen Scientist Project Manager and Patient Experience Manager were involved in the meetings and have invited \#PUPRU to attend the NHS Citizen's Panel Event to be held at the end of March in Salford. The event is underpinned by NHS strategy of 'reshaping of services to put patients at the centre and to better meet the health needs of the future', aiming to get those who live, work or access primary health care services in Salford involved in conversation. Presentations, interactive workshops and information stands will be provided at the event in three key topics:

- Salford Standards: Awareness raising of how this will benefit patients

- GM Devolution: 'Our Salford'

- Awareness of cancer needs in Salford

A prototype 'questionnaire device' (see Figure 2.6 below) has been developed based on Raspberry Pi, which will be tested at the event to gauge participant engagement and gather feedback on the quality of service, by using convenient input/output methods. 


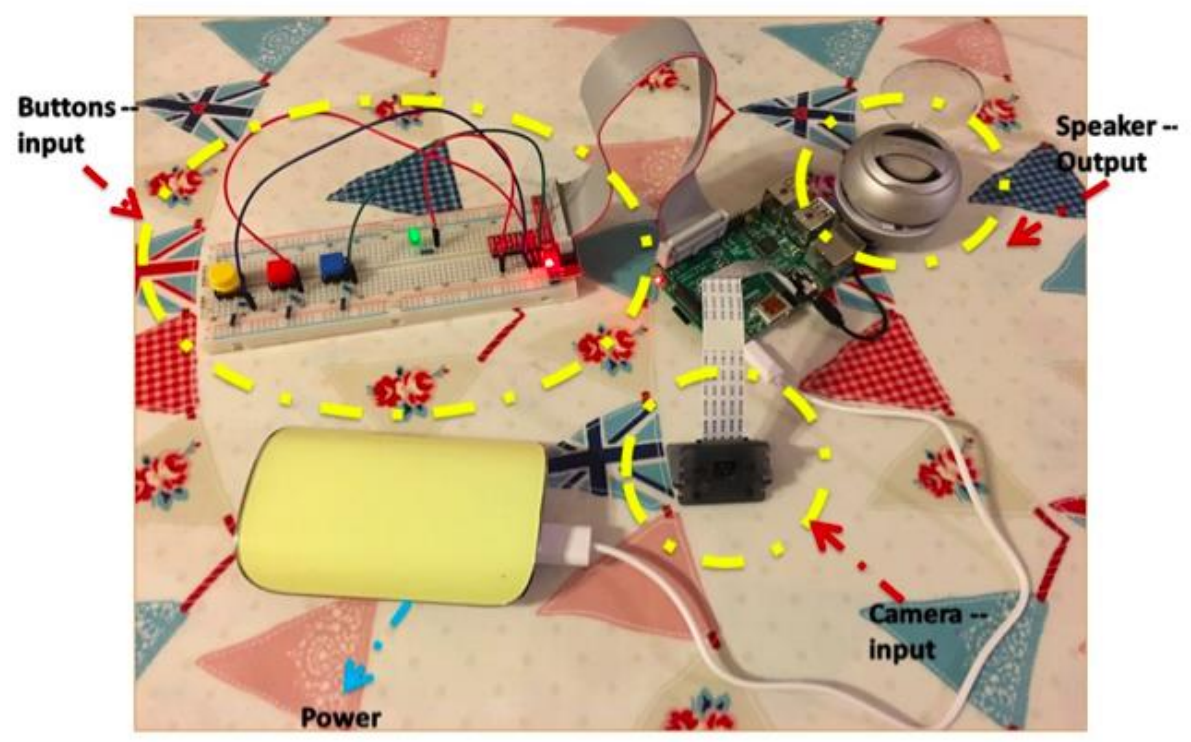

Figure 2.6 Raspberry Pi 'Questionnaire Device’

As illustrated above, there are two inputs captured from participants. These are i). the camera and button panel, and ii). an output channel from Raspberry Pi which is connected to a speaker. When a participant approaches the device, motion detection by camera will boot the questionnaire program automatically. A robot voice will deliver questions that are pre-set by the program one-by-one, waiting for participants to press colored button on the button panel to give their choices. When the questionnaire is finished, camera will re-start to ready to detect the next participant, which will repeat the previous process ad infinitum. The collected data will be stored on SD card of Raspberry Pi for analysis.

Because of the simplicity of the device, the questionnaire can be designed to align with four key issues facing an organisation, in the closed question format. In the demonstration version produced for the NHS Salford Citizen's Panel event, five questions suggested by NHS Salford Clinical Commissioning Group have been programmed:

1. Are you enjoying the event today? Blue button for Yes, Red button for No, Yellow button for So so

2. Would you come to a future event? Blue button for Yes, Red button for No, Yellow button for Maybe

3. What have you most liked about today? Blue button for Salford Standards, Red button for GM Devolution, Yellow button for Awareness of Cancer Needs

4. What did you least like about today? Blue button for Salford Standards, Red button for GM Devolution, Yellow button for Awareness of Cancer Needs

5. What would you like to see at future events? Blue button for Information about Health Services and Changes, Red button for Patient/Community Stories, Yellow button for Market Stalls

Since the writing of this paper has been carried out before the event, the authors are unable to provide the data collected from the event and complementary observations and interviews of participants using the Raspberry Pi driven questionnaire. However, as a continuous SAP research, data collection and analysis results will be reported in the next academic paper. It will also be used to inform the next step collaborations between the NHS and \#PUPRU which will integrate Raspberry Pi with other emerging technologies such as touch tables and beacons in a wider field.

\section{4 \#PUPRU Technologies (3): Beacons}

\subsubsection{Introduction to Beacons and their use in industries}

Beacons are small sensors which can be stuck anywhere to provide context and micro-location to smart devices. In a retail environment they have been successfully used to drive customer loyalty and in-store sales (Perka, 2016). Beacons are proximity-based, sending Bluetooth signals to a customer's mobile device when they within 50-100 feet of the device, to automatically trigger personalised coupons, offers, and loyalty rewards. They can also enable contactless payments, speeding up checkout process (Close, 2016). Retail giants have begun 
experimenting with beacons and the trend is catching on (Huffpost Business, 2016). Smaller retailers could be fast followers in adoption because of low associated costs, relative ease of implementation, and growing consumer preference to the use of mobile phones in stores, academically referred to as "showrooming (Kotler, 2012)”.

Nowadays, beacon technologies have been used $\mathrm{n}$ a retail context for the following reasons:

1. Customer convenience - Consumers increasingly use their mobile apps to comparison shop in the store, need attention diverted away from competitors like Amazon by triggering offer at the moment they are likely to purchase.

2. Enhanced shopping experience - Retailers need to move away from a transactional mindset to a focus on enhancing shopping experience, giving customers more than expected. This can be done through beacons pushing personalised coupons, offers, and rewards.

3. Affordability - The low cost of beacon technologies makes them accessible to small businesses.

4. Competition with larger retailers - Typically disruptive technologies would be only accessible by larger retailers, but the low cost of beacons levels this playing field.

5. Customer intelligence - Beacon-enabled apps collect data on customers' spending habits and product preferences, enabling creation of personalised, immediate and targeted offers.

Beacon technologies have the potential to be adopted in other areas of business as well as educational and public sectors. The authors present potential use cases in two categories (MoWow, 2016):

1. For customers: e.g. push notification, broadcasting, self-guided tours, social networking functions, parking information $\&$ assistance, location and information at conferences and events.

2. For Business Owners/Sector Managers: e.g. tracking items within the company via mobile device accelerometers, slow/full day analysis that optimises flow and services, understanding customer preference.

\subsubsection{The Beacons in \#PUPRU}

\#PUPRU has 3 beacons made by Estimote, colored Ice, Mint and Blueberry (see Figure 2.7 below)

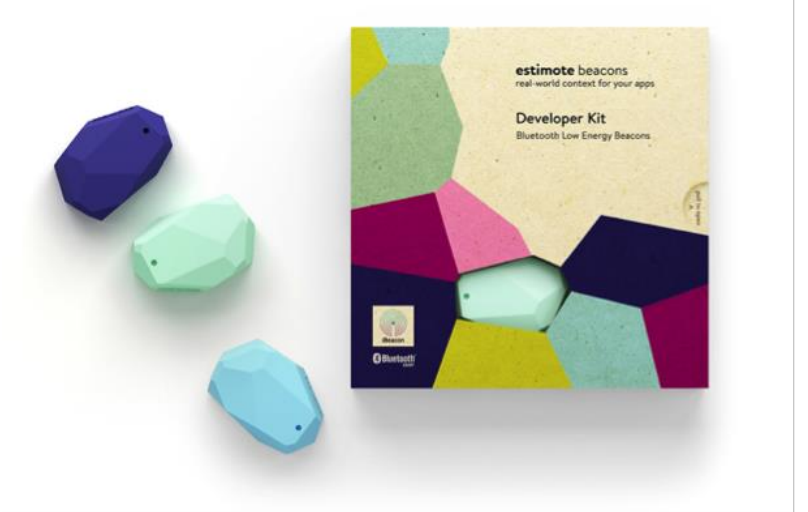

Figure 2.7 Estimote Beacons (Estimote, 2016)

Some potential use cases of beacon technologies in health care services are suggested by the authors as below:

- Navigation of buildings and spaces - use of beacons as a virtual map and to show helpful information

- Geo-location - location tracking of patients and visitors

- Analysis of people as they move throughout a hospital - identify footfall, hotspots or heat-maps

- Presentation of information in context to location - show information about the nearby clinics, ward and facilities

- Present visitors with live information - queuing times, bookings and offers

- Smart signage - translation of advertisements or visitor information based on smartphone settings

- Tracking of assets and stock - follow the movement of large items around hospitals

- Distributed networks - some newer types of beacon are able to communicate with each other to act as wireless access points

- Intelligent healthcare environments - access authorisation, patient tracking and monitoring and access to patient records 
In order to test some of the ideas listed above, for the NHS Salford Citizens' Panel Event described in Section 2.2.3, a beacon demonstration application has been developed to provide information to users of two stalls (i.e. the Cancer Prevention Stall and the Greater Manchester Fire Service 'Safe and Well' project Stall) and one information point (i.e. Greater Manchester Devolution and Locality Plan) at the event. 15 Samsung tablets will be taken to the event with the App installed for participant experiment and observation to be recorded so as to evaluate the usability of beacon technologies as a public sector event.

At the event, the three beacons will be placed where stalls and information point are located. Participants wishing to know more details about what is happening in each place can use a tablet and relevant information will be displayed on screen when they are near to a beacon (see Figure $2.8-2.10$ below):

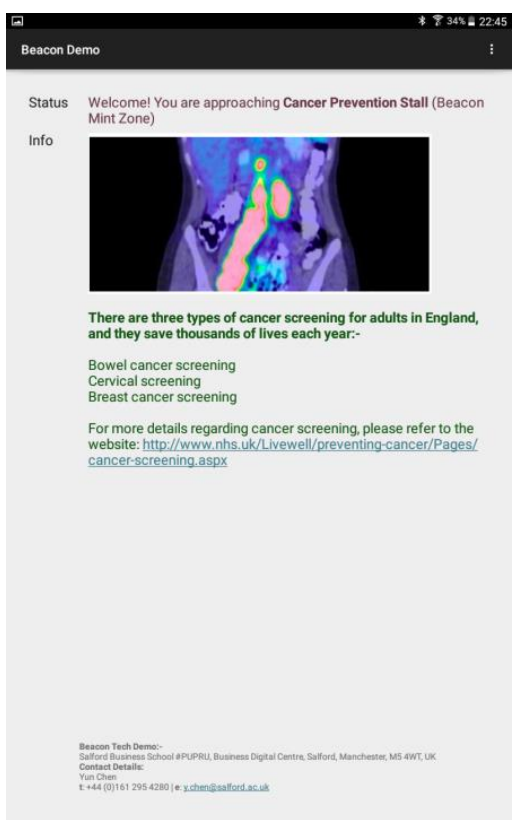

Figure 2.8 Cancer Prevention Stall (Beacon Mint Zone)

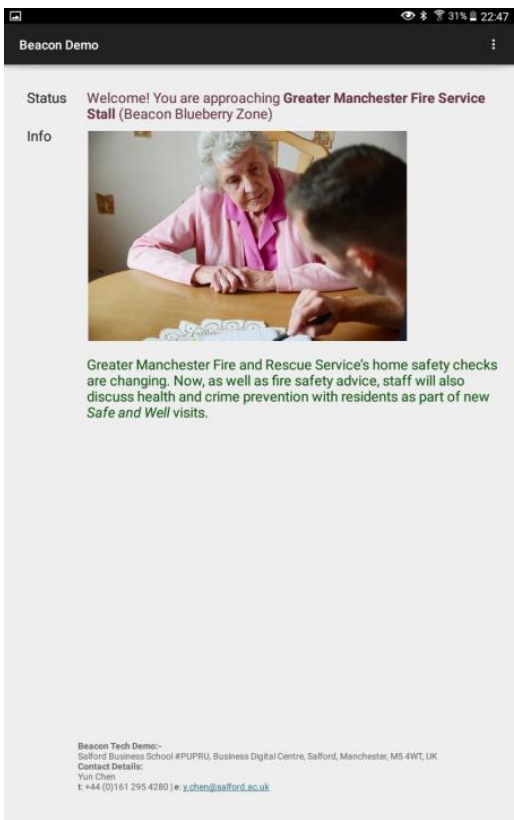

Figure 2.9 Manchester Fire Service 'Safe and Well' Project Stall (Beacon Blueberry Zone)

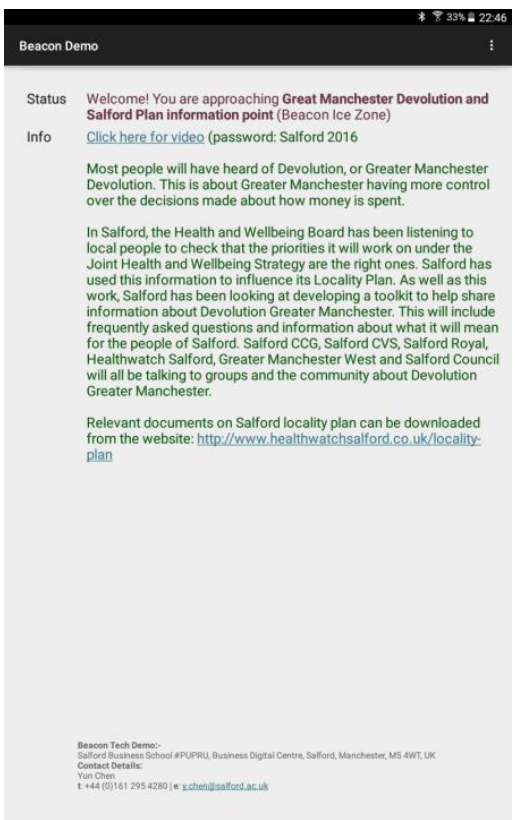

Figure 2.10 Great Manchester Devolution and Salford Plan (Beacon Ice Zone)

\subsection{Summary}

In this section, the key technologies, their potential business scenarios and experiments the authors have undertaken with \#PUPRU have been discussed. The next step for the \#PUPRU team will be to integrate all these technologies and evaluate their potential impact on business strategies in different live projects. This will be described in the following session.

\section{III. \# PUPRU LIVE PROJECTS - NEXT STEP}

\section{\#PUPRU beacons: in collaboration with Ericsson Telecommunication}

The \#PUPRU team have recently demonstrated the different technologies to the senior management team of Ericsson Telecommunications logistics centre based in the midlands. The Ericsson Team were given an overview of what the potential of the various technologies might offer. This demonstration was followed by a tour of the Ericsson logistics centre and a walk through of the key procedures was undertaken together with timeframes, bottlenecks and revising of business models were discussed. A shared understanding could then undertaken and this enabled a degree of clarity on potential business problems to be made followed by a cocreation of possible solutions using the technologies. The following business problems were identified for an exploratory study: the construction of telecommunication cabinets is a complex process, each cabinet is bespoke and is made up of hundreds of individual parts that require 'picking' from a warehouse prior to being built by semi-skilled engineers. These are both lengthy processes that if reduced or streamlined even in a minor way would have an impact on profit margins. The use of sensors could to be used to map and gather data of the 'picking' process that can then be analysed for time frames, potential bottlenecks and warehouse layout. The sensors can also be used to push notifications throughout the centre on training, stock levels or any business communications. The next business problem is inventory management and further discussions are planned for the proposed use of $3 \mathrm{D}$ printers to aid this part of the business. 


\section{\#PUPRU and Rapid prototyping for manufacture}

Recent discussions with a wool and clothing manufacturer have shown that there is interest in understanding how rapid prototyping could be used to disrupt their traditional Victorian manufacturing process. This is increasingly of interest within the garment manufacturing industry where $3 \mathrm{D}$ printing is a relatively new process. It said, recent devices that are being developed to print garments, eliminating waste and decreasing the time to develop a product have started to emerge (Kickstarter, 2016). Technologies like this will undoubtedly disrupt the traditional factory manufacturing environment. Traditional 3D printing will also be considered in relation to maintenance within the factory environment where the age of some essential machines causes issues with supply of parts and spares. As discussed earlier, this has been shown to be effective in other industries (Karagol, 2014; Stratysis, 2013) that need precision spares produced for complex machinery.

\section{\#PUPRU beacons: collaboration with Wipro Digital and a "Dutch Supermarket Chain"}

In a potential collaboration with Wipro Digital the \#PUPRU team will research ways in which beacons can be used in retail to drive sales and gather data on the behaviour of consumers in a Dutch supermarket chain. Some potential uses of beacons in retail have been discussed in this paper. But are there further uses for beacons within retail, and could they be used to gather even more granular data such as how people interact with a physical space? Furthermore, what extra intelligence could be provided to a business using these technologies?

\section{\#PUPRU beacons used to gather granular footfall data to understand human interaction with buildings: Media City UK campus, NHS, Hotel Football, TB Ramsden}

With various strategic partners Salford Business School is intending to explore how granular intelligence data enabling business operators to understand how people interact with their buildings, so as to increase revenue and improve profitability through actionable insight. Understanding interaction within a premises could help operators pinpoint areas where profits can be maximised, grow customer conversion, control queue management, increase sales, and inform marketing and merchandising decisions. There is also a heightened need for property managers and retail operators to maximise the value of their assets. Understanding footfall could potentially generate greater understanding of consumer behaviour and pinpoint where return on investment is and is not being generated.

Our quayside campus at Media City causes debate, because although it places the university at the heart of the creative and digital industry in the city, there are questions about how effectively the space is used. Within the NHS there is pressure to staff accordingly to address the needs of the customers whilst balancing budgetary constraints. In retail hospitality the need to maximise profits on key sales days is clear: understanding of how customers and staff interact with a hospital building could streamline efficiency, and put people in the right place to drive sales at the crucial moment. In the traditional manufacturing environment of a woollen mill there has been very little research carried out into how the building is used and what could be done to drive efficiency and profitability.

\section{\#PUPRU at the SPARC Conference: interaction installation and e-behaviour study}

\#PUPRU will be set up in the MediaCityUK foyer during the SPARC conference to demonstrate the range of technologies and start conversations with post-graduate students and staff that encourage potential collaborations throughout the schools. Additionally, it will be used to host a demonstration of our FootyFit.co.uk project, encouraging people to install and try the application and give feedback. A study of ebehaviour will be carried out using the data, with participation encouraged by a friendly competition looking at who can do the most steps during the duration of SPARC.

\section{CONCLUSION}

In conclusion the creation of \#PUPRU has created an opportunity to engage both students and external organisations looking at how emerging technologies can be used in enterprise innovation and business strategy in practice. The authors would like to summarise the next step of \#PUPRU in the following three directions: 
Within the school \#PUPRU complements the curriculum. It has been embedded into the undergraduate Business Information Technology course. The People and Computing module is designed to develop understanding of the deployment, taxonomy, theory and practice of human-computer interaction and interactive systems. In this module the students are given \#PUPRU as a case study and are tasked to produce a prototype for a digital presence for the research unit. Through this they gain an appreciation of the \#PUPRU disruptive technologies impact on organisations and society in general. At the same time this creates awareness in the learner of SAP and methods that align strategy, technology and business needs centrally in design and development processes.

Our Business Innovation Project (BIP) gives our M.Sc. and MBA students the option to complete the dissertation part of their studies through a live industry case study. The brief is defined by the partner organisation, and the student works to meet business objectives. The student applies theory learnt on their course and the organisation receives consultancy in a business-critical area. The technologies of \#PUPRU can be used as an action research tool for businesses wishing to explore disruptive technologies. Data gathered through these researches can be used to form the students' dissertations and be fed back into the umbrella \#PUPRU research.

\section{Using \#PUPRU in Research}

\#PUPRU provides Salford Business School and Center for Digital Business with a platform that supports research into business exploitation, implementation and integration of digital technologies, tools and methods. Recent reports (The Rt Hon. the Lord Heseltine of Thenford, 2012) have focused attention on the provision of academic support to the small and mid-sized business community, and generating local conditions that rebalance the economy away from overdependence on the City. Despite successes of business schools, it is evident that their full potential to support innovation and stimulate growth is not realised. What is clear is that industry engagement with schools at local and national level has been variable and this also reflects the debate as to the role and orientation of business schools as a whole. Various approaches to drive and create commercially viable products through industry collaboration that share \#PUPRU characteristics are evident (University of Liverpool, 2016). Within the University of Salford the recent creation of Industry Collaboration Zones (University of Salford, 2015) has created an opportunity to in theory drive engagement with business, solidifying the sustainability of the school and maximising the flow of technology and innovation research with strategic industry partners. There is further alignment with the $\mathrm{PhD}$ of one of the authors' of the paper, which is examining the integrity of business technology innovation in the academic environment. This will look at multicases of \#PUPRU in the Salford Industrial Collaboration Zones as a method of engaging with industry through consultancy and research. Many further opportunities for doctoral research are possible in relation to \#PUPRU and technologies used. Another doctoral research is investigating of the impact of 3D printing implementation on supply chain designs with the overall aim of developing an addictive manufacture implementation framework.

\section{Using \#PUPRU in Business}

Design spirits are usually associated (and becoming more popular) within the digital sector and possibly echo a different emerging attitude to approaching the web design process ensuring that UX has a prominent role to play when meeting client and their user's needs. On reflecting on what is often discussed with businesses who have enquired how the \#PUPRU might benefit them, a distinct business need is emerging - Salford Business School is developing a framework to facilitate innovative problem solving design spirits. Greater Manchester has a long history for being innovative, it was at the heart of the Industrial Revolution and now the creative industries are crowding into the city in a similar manner. But how do you join the party and learn how to be creative, to be an innovator or how to unlearn embedded working practices? Organisations today are time-starved, working in a 'Groundhog Day' manner, fire-fighting problems; they don't have the luxury of the multinationals with commissioned creativity spaces and dedicated time out of the working day to explore ideas or problem solving. Smaller organisations struggle to afford timeout to reflect in bespoke spaces; however it is the acknowledgment of empowering the notion to be creative, and facilitate the 'how to' explore and develop new ideas that are both fundamental and crucial for sustainability. The proposed problem-solving design spirits will look to deliver possible solutions in 48 hours using a range of creative thinking techniques and tools to fit with different business models. This will look to 'change the way your business thinks' or offer 'alternative approaches to the development of new designs and products' through:

- Business model generation

- Bespoke solutions for complex business problems

- Building of creative thinking skills and techniques

- Innovative thought about how to create new business opportunities for the market place 
The additional benefit of \#PUPRU design spirits will be that they are facilitated by a team of experienced educators and academics.

Toffler (1970) predicted a future where technology would change things so rapidly that people would be unable to fully adjust to changes before a new emerging technology shifted the paradigm of an industry or business again. Whether or not people have reached this point there is no denying the rapid pace of technological change today. Many traditional enterprises have historically been slow to adapt to and adopt emerging disruptive technologies. Although this may have been true in the past it is becoming increasingly less so as smaller players manoeuver to take advantage, impacting the sales of their major commercial competitors. The industry drive is to react faster than ever to new technologies, finding ways to integrate them into business models and strategies. These technologies alone are rarely the key to economic success: organisations create value through the alignment of technology and business strategies. Through doing this, as discussed in this paper, they manage relationships, capital and assets, and leverage information in new ways. \#PUPRU looks to engage with organisations with a "design spirit", looking to integrate emerging disruptive technology into their strategies and develop a framework for the SAP approach in enterprise innovation.

\section{REFERENCES}

- 3D-Model (2016). 3D-Model [ONLINE] Available at: http://www.3d-model.ch . [Accessed 19/03/2016]

- Accenture (2016). Big Bang Disruption: The innovator's disaster. [ONLINE] Available at: https://www.accenture.com/us-en/insight-outlook-big-bang-disruption-innovators-disaster.aspx . [Accessed 20/03/2016]

- AEB (2014). Six theories about how 3D printing will change logistics. [ONLINE] Available at: http://documents.aeb.com/brochures/en/aeb-white-paper-3d-printing.pdf . [Accessed 19/03/2016]

- aokley.com (2013). How to Make a Raspberry Pi Lego Robot: Part 1. [ONLINE] Available at: http://www.aoakley.com/articles/2013-09-19-raspberry-pi-lego-robot-part1.php . [Accessed 19/03/2016]

- BBC (2012). Game Group goes into administration, closing 277 stores. [ONLINE] Available at: http://www.bbc.co.uk/news/business-17512143 . [Accessed 19/03/2016]

- Business Insider (2105). People aren't using mobile phones for voice calls anymore. [ONLINE] Available at: http://uk.businessinsider.com/ee-stats-on-decline-of-voice-calls-in-uk-2015-10 . [Accessed 19/03/2016]

- Christensen, C., (1997). The innovator's dilemma : When new technologies cause great firms to fail (The management of innovation and change series). Boston, Mass.: Harvard Business School Press.

- Close (2016). Close: A new BEACON of light to guide you. [ONLINE] Available at: http://www.closepayment.com/beacon/ . [Accessed 20/03/2016]

- Creative Entrepreneur (2015). About - Creative Entrepreneur. [ONLINE] Available at; http://creativeent.co.uk/about/ . [Accessed 19/03/2016]

- Digital Trends (2015). Nike was just granted a key patent for 3D printed shoe technology. [ONLINE] Available at: http://www.digitaltrends.com/cool-tech/nike-patents-3d-printed-shoetechnology/\#ixzz43ODpsaGz . [Accessed 19/03/2016]

- Estimote (2016). Estimote: Real-world context for your apps. [ONLINE] Available at: http://estimote.com . [Accessed 21/03/2016]

- Euromonitor International Passport Database [ONLINE] Available at: http://www.euromonitor.com/passport [Accessed 15/02/2016]

- Formlabs (2016). The Form 1+. [ONLINE] Available at: http://formlabs.com/products/3dprinters/form-1-plus/ . [Accessed 19/03/2016]

- Gartner (1) (2015). Gartner Reveals Top Predictions for IT Organizations and Users for 2016 and Beyond. [ONLINE] Avaiable at http://www.gartner.com/newsroom/id/3143718 . [Accessed $19 / 03 / 2016]$

- Gartner (2) (2015). Gartner Says Worldwide PC Shipments Declined 9.5 Percent in Second Quarter of 2015. [ONLINE] Available at: http://www.gartner.com/newsroom/id/3090817 . [Accessed 20/03/2016]

- Gibson, I., Rosen, D. W., \& Stucker, B. (2010). Additive manufacturing technologies (pp. 1-3). New York: Springer.

- Holmström, J., Partanen, J., Tuomi, J., Walter, M. (2010). Rapid manufacturing in the spare parts supply chain: alternative approaches to capacity deployment. Journal of Manufacturing Technology Management 21 (6), 687-697. 
- Huffpost Business (2016). How Bluetooth Beacons Will Transform Retail in 2016. [ONLINE] Available at: http://www.huffingtonpost.com/kenny-kline/how-bluetooth-beaconswil_b_8982720.html. [Accessed 20/03/2016]

- Imison, C., Poteliakhoff, E., \& Thompson, J. (2012). Older people and emergency bed use: exploring variation.

- ITPro (2016). The best projects to try with the Raspberry Pi Zero. [ONLINE] Available at: http://www.itpro.co.uk/mobile/21862/raspberry-pi-top-20-projects-to-try-yourself . [Accessed 19/03/2016]

- Johnson, G., Withington, R., Scholes, K., Angwin, D., Regner, P. (2015). Fundamentals of Strategy (Third Edition). Pearson Higher Education.

- Karagol, B. (2014). 3D Printing: What does it offer and for whom? [ONLINE] Available at http://stps.metu.edu.tr/sites/stps.metu.edu.tr/files/STPS-WP-15-02_0.pdf [Accessed 20/02/2016]

- Khajavi, S. H., Partanen, J., \& Holmström, J. (2014). Additive manufacturing in the spare parts supply chain. Computers in industry, 65(1), 50-63.

- Kickstarter (2106). Electroloom - The World's First 3D Fabric Printer. [ONLINE] Available at: https://www.kickstarter.com/projects/electroloom/electroloom-the-worlds-first-3d-fabric-printer . [Accessed 20/03/2016]

- Kotler, Philip (2012). Principles of Marketing (15th Edition). Prentice Hall. p. 411.

- Luxexcel (2016). The Evolution of 3D Printing. [ONLINE] Available at: http://blog.luxexcel.com/3dprinting/evolution-of-3d-printing/ . [Accessed 19/03/2016]

- MoWow (2016). Over 100 use cases and examples for iBeacon technology. [ONLINE] Available at: http://blog.mowowstudios.com/2015/02/100-use-cases-examples-ibeacon-technology/ . [Accessed $21 / 03 / 2016$

- New Scientist (2012). US military gets into the 3D printing business. [ONLINE] Available at: https://www.newscientist.com/article/mg21628875.100-us-military-gets-into-the-3d-printing-business/ . [Accessed 19/03/2016]

- HNS (2013). The NHS belongs to the people: A call to action. [ONLINE] Available at: https://www.england.nhs.uk/wp-content/uploads/2013/07/nhs belongs.pdf. [Accessed 20/03/2016]

- Pearlson, K. E., Saunders, C. S., \& Galletta, D. (2016). Managing \& Using Information Systems, Binder Ready Version: A Strategic Approach. John Wiley \& Sons.

- Perka (2016). Perka Mobile Loyalty. [ONLINE] Available at: http://perka.com . [Accessed 20/03/2016]

- Raspberry Pi (2106). Raspberry Pi. [ONLINE] Available at: https://www.raspberrypi.org . [Accessed $16 / 03 / 2016]$

- Stratysis (2013). Compressing the design cylce at Ducati. [ONLINE] Available at: http://usglobalimages.stratasys.com/Case\%20Studies/Automotive/SSYS-CS-Fortus-Ducati-0713.pdf? $v=635139936108916076$. [Accessed 19/03/2016]

- Techradar (2013). Raspberry Pi: The hidden business benefits. [ONLINE] Available at: http://www.techradar.com/news/computing/raspberry-pi-the-hidden-business-benefits-1145649. [Accessed 19/03/2016]

- The University of Liverpool (2016). Sensor City: A global hub for sensor technologies [ONLINE] Available at: https://www.liverpool.ac.uk/sensor-city/ . [Accessed 19/03/2016]

- The Rt Hon. the Lord Heseltine of Thenford (2012). No Stone Unturned: in the pursuit of growth, BIS

- Thingiverse (2016). Thingiverse. [ONLINE] Available at: http://www.thingiverse.com . [Accessed $19 / 03 / 2016]$

- Toffler, A. (1970). Future shock. London: Bodley Head.

- University of Salford (2015). Industry Collaboration Zones - the way forward for our University? [ONLINE] Available at: http://staff.salford.ac.uk/newsitem/4746 . [Accessed 15/03/2016]

- Wohlers, T., \& Gornet, T. (2011). History of additive manufacturing. Wohlers Report: Additive Manufacturing and 3D Printing State of the Industry Annual Worldwide Progress Report.

- Ventola, C. L. (1) (2014). Medical applications for 3D printing: current and projected uses. PT, 39(10), 704-711.

- Ventola, C. L. (2) (2014). Mobile devices and apps for health care professionals: uses and benefits. Pharmacy and Therapeutics, 39(5), 356.

- Wunker, S. (2012). Better growth decisions: Early mover, fast follower or late follower? Strategy \& Leadership, 40(2), 43-48.

- Wyatt-Haines, R. (2007). Align IT: Business Impact Through IT. John Wiley \& Sons 